University of Wollongong

Research Online

$1-1-2017$

Driver licensing and health: A social ecological exploration of the impact of licence participation in Australian Aboriginal communities

\author{
Patricia Cullen \\ University of Sydney, University of New South Wales \\ Kathleen F. Clapham \\ University of Wollongong, kclapham@uow.edu.au \\ Kate Hunter \\ University of Sydney, University of New South Wales \\ Bobby Porykali \\ University of New South Wales \\ Rebecca Q. Ivers \\ University of Sydney, University of New South Wales, Flinders University, rivers@uow.edu.au
}

Follow this and additional works at: https://ro.uow.edu.au/ahsri

Research Online is the open access institutional repository for the University of Wollongong. For further information contact the UOW Library: research-pubs@uow.edu.au 


\title{
Driver licensing and health: A social ecological exploration of the impact of licence participation in Australian Aboriginal communities
}

\author{
Abstract \\ Introduction: Reduced licence participation in Aboriginal and Torres Strait Islander communities \\ contributes to transport disadvantage, higher rates of transport-related morbidity and mortality. This \\ study will incorporate a social ecology framework to better understand the economic, social inclusion and \\ cultural impacts of licensing at all levels of the system from individuals, families, communities and the \\ socio-political environment. Methods: Qualitative methods underpinned by a social ecology approach \\ triangulates in-depth interviews $(n=17)$ and community discussion groups $(n=21)$. Analysis was \\ inductive and deductive. Results: The impacts of licence participation were evident at multiple levels of \\ the social ecology and it emerged that licensing greatly impacts the mobility of individuals, families and \\ communities. Beyond mobility, the data amalgamated into four main themes: 1) Social and economic \\ opportunity; 2) Access to services; 3) Cultural identity; and 4) Autonomy and the justice system. \\ Discussion: Reduced driver licensing is impacting individuals, families and communities with an immense \\ cost to multiple levels of the social ecology. This study has highlighted the value of licence participation \\ for cultural identity and community well-being. Further, licence participation interacts with persistent \\ inequity in the licensing and justice system and impacts on the capacity of individuals, families and \\ communities to function autonomously within the parameters of the law. Accordingly, policy should be \\ directed at facilitating equitable access to driver licensing to promote social inclusion. Licensing is not \\ simply a "Transport" problem; addressing this complex issue of health and social justice is a prime \\ example of the need for an intersectoral approach that targets change at the socio-political level to \\ improve the equity, health and wellbeing of Aboriginal and Torres Strait Islander people.

\section{Publication Details} \\ P. Cullen, K. Clapham, K. Hunter, B. Porykali \& R. Ivers, "Driver licensing and health: A social ecological \\ exploration of the impact of licence participation in Australian Aboriginal communities", Journal of \\ Transport and Health 6 (2017) 228-236.
}




\section{ABSTRACT}

\section{Introduction}

3 Reduced licence participation in Aboriginal and Torres Strait Islander communities

4 contributes to transport disadvantage, higher rates of transport-related morbidity and

5 mortality. This study will incorporate a social ecology framework to better understand the

6 economic, social inclusion and cultural impacts of licensing at all levels of the system from

7 individuals, families, communities and the socio-political environment.

\section{Methods}

9 Qualitative methods underpinned by a social ecology approach triangulates in-depth

10 interviews $(n=17)$ and community discussion groups $(n=21)$. Analysis was inductive and

11 deductive.

\section{Results}

The impacts of licence participation were evident at multiple levels of the social ecology and it emerged that licensing greatly impacts the mobility of individuals, families and communities. Beyond mobility, the data amalgamated into four main themes: 1) Social and economic opportunity; 2) Access to services; 3) Cultural identity; and 4) Autonomy and the

17 justice system.

\section{Discussion}

Reduced driver licensing is impacting individuals, families and communities with an immense cost to multiple levels of the social ecology. This study has highlighted the value of licence participation for cultural identity and community well-being. Further, licence participation interacts with persistent inequity in the licensing and justice system and impacts on the capacity of individuals, families and communities to function autonomously within the parameters of the law. Accordingly, policy should be directed at facilitating equitable access 
25 to driver licensing to promote social inclusion. Licensing is not simply a "Transport"

26 problem; addressing this complex issue of health and social justice is a prime example of the

27 need for an intersectoral approach that targets change at the socio-political level to improve

28 the equity, health and wellbeing of Aboriginal and Torres Strait Islander people.

29 Keywords

30 Aboriginal; injury; health equity; policy; driver licensing; transport disadvantage 


\section{1. INTRODUCTION}

2 Access to safe, reliable and legal transport is central to social inclusion and economic

3

4 participation. The capacity to access transport to maintain employment, education, socialise and access healthcare impacts the health and well-being of individuals, families and communities (Currie \& Senbergs, 2007; Rosier \& McDonald, 2011). Globally, Indigenous populations are known to be vulnerable to transport injury and transport disadvantage, for example Maori populations in New Zealand experience significant transport disadvantage, which has been described as ethnically mediated transport disadvantage (Pollack, Frattaroli, Young, Dana-Sacco, \& Gielen, 2012; Raerino, Macmillan, \& Jones, 2013). In Australia, Aboriginal and Torres Strait Islander people are more likely to experience transport disadvantage and there is an emerging focus on the relationship between transport, social inclusion, health and well-being (Delbosc \& Currie, 2011; Rosier \& McDonald, 2011; Scrimgeour \& Scrimgeour, 2008; Ware, 2013). Despite this progress, there is still a gap in the dialogue around transport disadvantage, which focuses on access to public transport and ownership of private cars, with little consideration of the impact that licence participation has on the mobility of individuals and families. This is particularly salient for Aboriginal communities as Aboriginal people are underrepresented in the licensing system, yet little is known about the direct impacts of licensing-related transport disadvantage on social inclusion and well-being in Aboriginal communities. To address this, the present study will incorporate a social ecology framework to explore the impacts of licence participation at all levels of the system from individuals, families, communities and the socio-political environment.

\subsection{Social ecology framework}

A social ecological framework used in this study has been previously used to better understand the social and environmental inequalities that underlie health disparities (Kok, Gottlieb, Commers, \& Smerecnik, 2008). The social ecological approach asserts that health is 
a function of the interrelationship between individual, interpersonal, community, sociopolitical and environmental influences (Richard, Potvin, Kishchuk, Prlic, \& Green, 1996). Further, this approach allows for examination of the complexities and connections between each level and is inherently suited to exploring public health issues that require an intersectoral approach.

\subsection{Intersectoral approach to licensing participation}

In the last decade, an intersectoral approach to public health has been endorsed and implemented globally to improve population health and reduce complex health inequities (Baum et al., 2013; Lawless et al., 2012). This approach recognises that tackling complex health inequities requires a commitment to action across multiple sectors of government and services to generate policies that systematically consider the implications and impact on population health. The South Australian (SA) government applied this approach to improve the health and wellbeing of Aboriginal people, which was driven by SA Thinker in Residence Professor Ilona Kickbusch (Kickbusch \& Buckett, 2010; Kickbusch, McCann, \& Sherbon, 2008). Among Kickbusch's (2008) recommendations was the assertion that driver licensing should be prioritised across policy sectors to positively impact mobility, access, opportunities, identity and autonomy within Aboriginal communities; this is reflected in Figure 1. This model of driver licensing participation echoes calls for research globally with Indigenous peoples to move beyond socioeconomic consequences to also consider the broader impacts of transport disadvantage on health and wellbeing.

\subsection{Transport disadvantage and social inclusion}

Due to the vastness of Australia, travel frequently involves private transport. For example in 2011 among employed people 15 years and over, almost two thirds travelled by private car as either a driver or passenger to work (Australian Bureau of Statistics, 2011). In terms of access to private transport, the Australian Institute of Health and Welfare (2014) reports that non- 
51 Aboriginal households had considerably higher car access (85\%) compared with Aboriginal

52 households $(51 \%)$. Public transport is a viable alternative to private transport, particularly in urban areas, however outside of urban centres public transport is limited and costly; for example, the ABS reports that $71 \%$ of Aboriginal adults in remote areas had no public transport compared to $18 \%$ in non-remote areas (Australian Bureau of Statistics, 2010). Correspondingly, public transport use was lower for Aboriginal people in remote areas (13\%) than non-remote areas (30\%) due to the lack of public transport options in remote areas (Australian Institute of Health and Welfare, 2014). Such difficulties accessing both public and private transport impact on the capacity of individuals and families to attend education, employment and essential services, which can have far reaching consequences on social inclusion and well-being. In terms of access to healthcare services, $16 \%$ of Aboriginal people cited lack of transport or excessive distance as a barrier, which was considerably higher in remote areas (22\%) than non-remote areas (15\%) (Australian Institute of Health and Welfare, 2014). While this is evidence that transport disadvantage is impacting Aboriginal communities, these figures do not reveal the extent to which licensing-related transport disadvantage is impacting the wellbeing and social inclusion of Aboriginal people.

\subsection{Licensing-related transport disadvantage}

Prior research demonstrates that Aboriginal people are underrepresented in the licensing system and overrepresented in licensing related incarceration and road injury (Cullen, Chevalier, Hunter, Gadsden, \& Ivers, 2017; Cullen, Clapham, Byrne, et al., 2016; Edmonston et al., 2003; Elliot and Shananhan Research, 2008; Helps et al., 2008; Henley \& Harrison, 2013; Ivers, Clapham, Senserrick, Lyford, \& Stevenson, 2008; Ivers et al., 2016; Ivers et al., 2011; Naylor, 2010; NSW Auditor General, 2013; Somssich, 2009). It is estimated that in NSW in 2011, Aboriginal people comprised only $0.4 \%$ of licence holders in NSW despite being $1.9 \%$ of the eligible population (NSW Auditor General, 2013). 
76 A 2012-13 survey that was conducted with 625 people 16 years or older in four Aboriginal

77 Community Controlled Health Services in NSW and SA reported that licensing rates varied between the sites $51-77 \%$, with one of the lowest rates reported in the urban location of Redfern (Ivers et al., 2016). The authors concluded that this may relate to the availability of public transport in urban areas. These results also highlighted that licence participation can be low even in populations that reside in well-serviced locations as community members still encounter substantial barriers to licensing. Ivers et al. (2016) reported that having a driver licence was significantly associated with higher odds of full-time employment and postsecondary education; those who held a driver licence (provisional or full) were four times more likely to be in full-time employment and two to four times more likely to have higher levels of formal education. The authors suggested that driver licensing can be viewed as a cause and consequence of socioeconomic disadvantage and that licensing inequality has far reaching impacts on the health and wellbeing of Aboriginal people. Evidently, low levels of licensing in both urban and non-urban communities is a barrier to education, employment and social inclusion, which can be particularly detrimental in non-urban locations where access to viable public transport can be limited (Elliot and Shananhan Research, 2008; Helps et al., 2008; Ivers et al., 2016). Given the far reaching consequences of licensing-related transport disadvantage, addressing the underlying causes requires a cross-government intersectoral approach. Despite this, the role of licence participation in Aboriginal communities has not been explored and little is known about the role that licensing may play in social inclusion. Accordingly, the present study seeks to explore the economic, social inclusion and cultural impacts of licence participation and the consequences for the health and wellbeing of Aboriginal people in NSW.

\section{METHODS}

Qualitative methodology has been employed to triangulate data from in-depth interviews and small community discussion groups. 


\subsection{Participants and context}

In accordance with the social ecological approach, purposive sampling was used to identify key informants from government agencies, community service organisations and community members (Table 1). Additionally, snowball sampling was used with all informants asked to recommend other potential informants with useful insights or unique perspectives; the number of interviews was determined by thematic saturation. Participants from government agencies $(n=5)$ were drawn from Transport for NSW, Attorney-General's Department, Legal Aid, Aboriginal Affairs. Service providers $(n=12)$ included managers and staff of licensing, employment and community support programs. Community members $(n=21)$ were drawn from two communities in NSW; Wagga Wagga and Taree. Wagga Wagga is a regional centre and the largest inland city in NSW, with a population of approximately 62,000 , of which $4.6 \%$ of people identify as Aboriginal and/or Torres Strait Islander (Australian Bureau of Statistics, 2015b). Taree is a regional centre situated on the Mid North coast of NSW, with a population of approximately 49,000 of which $5.4 \%$ of people identify as Aboriginal and/or Torres Strait Islander (Australian Bureau of Statistics, 2015a). In both of these locations, travel by private car is the main form of transport and accordingly a substantial proportion of residents travel to work by car; Wagga Wagga, (88\%) and Taree (89.5\%) (Australian Bureau of Statistics, 2015a, 2015b). Both Wagga Wagga and Taree have identified that licence participation is an issue for Aboriginal people in the community and have implemented a community-based driver licensing support program Driving Change, which is aimed at assisting young Aboriginal people to access the licensing system (Cullen, Clapham, Byrne, et al., 2016).

\subsection{Data collection and analysis}

Interviews were conducted by telephone or face-to-face by the first author, while the community discussion groups were moderated by an Aboriginal researcher and observed by the first author. Participants were encouraged to share stories and/or their experiences of 
licensing, transport and the social ecological impacts on individuals, families, communities and the socio-political environment. These were voice recorded and transcribed either by a professional company or the first author; analysis of the transcribed data was managed using Nvivo 10 software (QSR International Pty Ltd, 2012). The data analysis was concurrent with data collection to facilitate an iterative process. Initial codes were generated during data collection and transcription, which were then explored and developed in subsequent interviews. All transcripts were read through and the data assigned codes independently by two authors. Coding was reviewed and amalgamated into themes; discrepancies were resolved with consensus-based discussion. The thematic analysis was both inductive (emergent) and deductive (pre-determined) guided by Kickbusch (2008) model of licence participation. As part of this process, we derived the initial concepts for our analysis from the following components of Kickbusch's model: mobility, identity, opportunity and access. We used these overarching concepts to explore specific themes (e.g. mobility) within the data while not restricting the emergence of unanticipated or divergent themes. The analysis was conducted through the lens of the social ecological framework in order to explore the meaning at the individual, family, community and socio-political levels.

\subsection{Ethics}

This study was approved by the Aboriginal Health and Medical Research Council (AH \& MRC) of NSW. Aboriginal people have led or been involved at all stages of the study from design of interview guides, data collection, data analysis and interpretation. This has involved collaboration, capacity building and learning for Aboriginal and non-Aboriginal co-authors.

\section{RESULTS}

The impacts of licence participation were evident at multiple levels of the social ecology and it emerged that licence participation greatly impacts the mobility of individuals, families and communities. The issue of mobility was related to challenges that were specific to urban and non-urban communities. Beyond mobility, the data amalgamated into four main themes that 
were largely consistent with Kickbusch (2008): Social and economic opportunity; Access; Cultural identity; Autonomy and the justice system.

\subsection{Mobility}

Mobility was identified as fundamental to all aspects of participation and within this a driver licence was a conduit to mobility. There was consensus among informants that licence participation was essential in Australian communities due to the vastness of the geography and the necessary reliance on private transport. Informants identified the road safety benefits of licence participation and were emphatic that a licence was an enabler to multiple forms of social inclusion.

'There's all that stuff, getting to school, getting shopping, getting a job most importantly.... getting economic independence (that) having a licence enables' 'And the tree just gets bigger by getting them their licence, not only are you stopping them from being injured or killed in road accidents due to just getting in a car or stuff like that, their job prospects, young mothers, they can actually do things for their children' Several informants asserted that the impact of low licence participation and subsequent transport disadvantage is significantly worse in regional and remote communities. 'Not having a licence is a huge barrier to participation in everyday life activities, and that becomes more intense in regional and remote areas where a car is a fundamental necessity' 'Like having your licence, particularly in Taree, in a country town where public transport is lacking, having your licence is a big difference of just being able to function in this town' 'I think in the city we just don't see it as an issue, because you can just hop on a bus, you've got options but you don't have those transport options in those remote communities, so it's much more of a direct effect'

While other informants highlighted that it was a common misconception that people living in urban communities were not impacted by licence participation. 
'People just outside of Sydney in urban areas have more transport disadvantage than people in regional towns...... transport disadvantage and licensing is something that I am really passionate about, and the fact that we can't just say that this is something that exists in remote or regional communities'

'There's a view that it's more of a remote issue but disadvantage doesn't live in one location' While informants expressed differing views on the extent to which licence participation impacts urban settings that have alternative transport options, it was evident that reduced mobility is not simply an issue for regional and remote communities. There was consensus among informants that mobility and licensing are essential to the broader goals of participation.

\subsection{Social and Economic Opportunity}

Reduced capacity to pursue opportunities was strongly related to licence participation by informants, with employment and education being the most frequently cited opportunities. This was considered to be having an intergenerational impact at the individual and family level but also at a community level whereby reduced community capacity, educational outcomes and workforce participation was considered detrimental.

'Driver licensing came up as a barrier to employment ... this was one of the examples that someone gave me, we can get this girl a job at McDonalds after school but we can't get her home safely after work at night to take up that role, .... I see it as being really important, especially for young people getting them started in their career'

'It's like TAFE, we've got all these TAFEs in regional areas that no one can get to because they can't drive there'

Informants who were unlicensed reinforced this association between employment and licensing, describing employment prospects as the primary motivation for pursing a licence. 'It makes it easier to find a job. For me that's probably the only real reason, because a lot of the work that I want to do is - I need to be able to travel a lot' 
One informant related the issue of reduced opportunity to apathy in individuals, families and communities and felt that this contributed to substance misuse and tendency toward illegal activities.

'I do a bit of work up in Toomelah and Boggabilla, which is up about an hour north of Moree, on the border of Queensland and is largely an Aboriginal community, I think there is one school bus which goes from Toomelah to Goondiwindi, which is the local town where you can do shopping, which is actually in Queensland, but there's no other way of getting in or out of Toomelah otherwise. So you might turn up at Toomelah in the morning and there will be about 3 or 4 stolen cars, I'm not saying the lack of a licence leads to crime but the lack of opportunity means that people will do what they can to get home. They do what they have to get home'

'It all relates back to not being able to get employment. Then it has a spiralling effect that I've witnessed. If young people aren't working then they're getting into things that they've got time to get into, which is drugs and alcohol... people have nothing to do because they can't get work because you need a licence in our town and even one of the Aboriginal organisations in town don't accept applications for positions unless you've got a licence..... If they're not working then they're on Centrelink they're limited in what they can get and where they live and to escape that reality you look to drugs and alcohol and everything else that's wrapped up in it.'

Indeed, reduced opportunity was specifically highlighted by several informants as an acute concern in regional and remote communities, as was the limited availability and cost of public transport.

'The issue of not having a licence in rural communities is the lack of opportunity that goes with it' 


\subsection{Access}

Licence participation was identified as essential to accessing services including healthcare, shopping, social and cultural activities. Informants related this to the need for private transport and this was most frequently described as an issue in non-urban communities again due to the limited access and prohibitive costs of public transport.

'Sometimes it is a bit difficult to get down into town..... the buses come every hour, and sometimes if you miss it, you can't get in there unless you've got to catch a taxi, which is $\$ 13$ $-\$ 14^{\prime}$

Access to health services emerged as one of the main issues with direct impacts of licensing on health independently identified by informants. Further, informants expressed concern that the burden of chronic disease was greater if people did not have transport access to essential health services.

'It comes up as a barrier with health, access to medical appointments and things like that' 'Being able to take someone to hospital when they need to. The incidence of chronic disease in remote communities is very well documented so the ability to take people to the treatment that they require, or people might not get the treatment they require - so long term the costbenefit is lost as the sicker people get the harder they are to treat'

\subsection{Cultural Identity}

In terms of identity, informants recognised that Aboriginal people have strong cultural and kinship responsibilities that are difficult to meet without access to licensing and transport. Identity emerged as ‘cultural identity', encompassing family and kinship connections, whereby everyone belongs to both a people and a place or 'Country'. In particular, connection to Country and community were seen as important to Aboriginal peoples' sense of cultural identity and concept of health. Accordingly, respondents cited that access to a licence and transport was essential to meet cultural priorities, which are central to the health 
and well-being of individuals, families and communities. Cultural identity priorities included caring for Country, caring for family, transporting family and attending funerals. 'To conduct sorry business.... there are a whole lot of issues that are addressed just by having a licence’

Cultural identity was strongly connected to family, with licensing viewed as a means to provide and care for family. Community informants related that licence participation was important as it helped to provide transport for their family.

\section{'She's like "I'm gonna take mum for a drive”.... Her mum has some real mental health} issues, so for her to be able to help look after her mum because mum can't jump on buses' In terms of cultural identity, respondents also identified that there is a burden on licensed drivers in communities who are frequently called upon to provide transport to meet cultural and kinship responsibilities. Respondents felt that having few licensed drivers in a family or community can place a heavy burden on both the driver and passengers.

'You can understand, if someone can't give you a lift because they're running around doing things and that person's usually not only giving you lifts, they're probably giving other people lifts and they've got their own things'

\subsection{Autonomy and the Justice System}

In different cultures, autonomy can refer to individuals, family or community and assumes the right to exercise self-determination or self-governance. The autonomy of individuals or communities must function within the parameters of the justice system. In terms of licence participation, it emerged that increased contact with the justice system was a frequent impact of reduced access to licensing. Further, informants elaborated that the relationship between contact with the justice system and reduced licence participation was impacting the capacity of individuals, families and communities to function autonomously. Government informants lamented that exercising the right to autonomy and operating within the parameters of the law 
was discordant due to inequity within the justice system. This inequity primarily related to lengthy licence disqualifications and the fines enforcement system, which were identified as preventing equitable and autonomous participation.

'Fines is huge, we see people with 20000 dollars in fines, I think I've only seen one person with 40000, and then disqualifications until 2048 - massive disqualification periods is another issue'

'We have a fines system that isn't means tested - so if I forget to register my car, and I am fined for driving an unregistered car, well I'm employed so I can address that. But a $\$ 500$ fine for someone who is in receipt of benefits is completely crippling - so the fine you get is the same regardless of your means.......getting a fine, can't afford to pay the fine, then lose licence because the fine is unpaid, then they drive anyway because they have to, then get picked up for unauthorised driving, which just feeds into this cycle of secondary offending - I really believe that that secondary offending that comes from poverty or disadvantage is just a direct pathway into the criminal justice system. Then in NSW we have the Habitual Traffic Offenders scheme, which puts people off the road for years and years and years, with these crippling periods of disqualification.... Sometimes people can't drive for 15-20 years'

Further, informants reported that the system was creating apathy as licence participation was seen as unattainable, which combined with the need for transport, led to increased risky behaviours and unauthorised driving.

'A high crime rate, I believe, because they've got nothing to lose really. If they don't have a licence and stuff, well, that would give them incentive to not do anything bad because they may lose it'

'But what do you do if you live in Wilcannia, which is two hours til Broken Hill where the nearest supermarket is and that costs $\$ 15$ in a bus, you get in the car. People take risks, we see this in our work all the time - people have to get their kids to school, they have to get 
their partner to a doctor's appointment, they take the risk because they just don't have other transport options'

In terms of community autonomy, one informant related the following story, which highlights the impact that reduced licence participation can have on communities' autonomous capacity to simply avoid harm and function within the parameters of the law.

'There's a small community in Northern NSW and some floods were coming so the police came into town and said the floods will be here within 48 hours, you might want to think about moving on because this won't be a safe place to be. They came back a day later and no one had moved and they thought 'what's the story'? And they were told that there is all these cars here but none of them are registered and no one has a valid licence. So they were scared that because the police had come and told them to move that if they drove they'd be done for driving unregistered and unlicensed - the fines for that are a couple of thousand dollars and if that's your second or third offence you go to gaol. So the police said we're just going to drive and we're not going to look back, so then the community packed up and moved. But this is the kind of level we are talking about, it's extraordinary really, almost third world, and this is only a matter of a few years ago it's not in the 1950s'

Individual and communities' right to autonomy assumes a fair and equitable system of justice. Informant perspectives however revealed that there is inherent inequity within both the licensing and justice system that impedes autonomous participation.

The impacts of licence participation were evident at all levels of the social ecology and had far reaching consequences beyond transport mobility. While licensing was an important conduit to accessing healthcare and services, the impact of licensing on health was also related to the underlying social determinants of health. Accordingly, licence participation was seen to positively impact social and economic opportunity, cultural identity and autonomy within the justice system. The benefits of licence participation for individuals, 
families and communities generates a bottom-up effect that positively impacts and alleviates burden across multiple Government departments and agencies; this association is depicted below (Table 2).

\section{DISCUSSION}

While much of the previous research on licence participation in Aboriginal communities has focused on the barriers to licensing, this study has explored the impacts of licence participation within the context of NSW from the perspective of government, service provision and community. The use of a social ecological approach revealed direct impacts of licence participation at all levels of the system including socioeconomic, health and justice impacts. Informants described the benefits of having a licence on individuals' mobility and also the impact of licence participation on communities and the broader goals of social inclusion. Further, it emerged that licence participation in Aboriginal communities has far reaching effects that benefit all levels of the social ecology from individuals and families through to Government departments and agencies.

The study was also informed by the Kickbusch (2008) model of licensing that depicts the benefits derived from licensing-related mobility. The themes that emerged from the present study closely aligned with Kickbusch (2008) particularly in terms of access and opportunity. The present results confirm that licensing is conducive to pursuing opportunities, with informants at all levels of the system emphasising that licensing is a facilitator to engaging with education and employment opportunities. This reinforces Ivers et al. (2016) that reported a strong association between licensing, and social determinants of health including education and employment. The present study extends these results to elaborate on other impacts of licence participation, including cultural identity and access to services.

In terms of access, previous research has reported that reduced licence participation in both urban and non-urban communities is a barrier to mobility and access to services; however this form of transport disadvantage is considered particularly detrimental in non-urban locations 
where access to viable public transport can be limited. (Currie \& Senbergs, 2007; Elliot and Shananhan Research, 2008; Helps et al., 2008; Ivers et al., 2011). While this was confirmed in the current study, the results were less emphatic than previous studies that the impacts of licence participation in urban communities is mitigated. This study presents a compelling picture of urban transport disadvantage due to reduced licence participation that has far reaching consequences for social inclusion, access to services, health and wellbeing. Further, residing in an urban location does not restrict the need to travel to distant locations of cultural or personal significance. This can be particularly important for Aboriginal people to fulfil cultural or family responsibilities, yet without access to a licence and/or private transport this can be impracticable, particularly in areas not well serviced by other forms of transport.

The importance of licensing to cultural identity is consistent with previous research that has shown that transport is essential to Aboriginal peoples' sense of cultural identity, responsibility and wellbeing (Currie \& Senbergs, 2007; Elliot and Shananhan Research, 2008; Helps et al., 2008; Raerino et al., 2013). Further, cultural and kinship responsibilities can involve distant travel to locations that may not be easily accessible without private transport. According to the Australian Institute of Health and Welfare (2015) in 2012-13, approximately $70 \%$ of Aboriginal adults identified an area as their homelands or traditional Country, however only one quarter (25\%) of Aboriginal adults lived on their homelands or traditional Country, which was most likely among those in remote (36\%) and very remote areas (52\%). While Aboriginal people may not reside in their traditional homelands, the connection to Country is enduring and considered different to that of other Australians, and the capacity to both travel and transport family to these locations therefore fulfils an important aspect of cultural identity.

Culturally, there are differing views on autonomy, which can refer to an individual, family or communities' autonomy. Autonomy implies the right to self-determination and self- 
governance, which in accordance with the 2007 United Nations Declaration on the Rights of Indigenous Peoples is a fundamental human right and also a right to Indigenous peoples as a collective (United Nations, 2008). Yet the present results indicate that individual and community autonomy may be at risk due to inequity within the licensing and justice system. In particular, the fines enforcement system has been identified by previous research as markedly inequitable and culpable for creating and entrenching poverty (Cullen, Clapham, Byrne, et al., 2016; Cullen, Clapham, Hunter, Treacy, \& Ivers, 2016; Golledge, 2006; Naylor, 2010; NSW Auditor General, 2013). Further, there is growing concern that such systemic inequity is contributing to an over-representation of Aboriginal people in prison (Anthony \& Blagg, 2012; NSW Auditor General, 2013). Autonomous individuals and communities must function within the parameters of the justice system, yet aspects of this system have been identified as unjust for vulnerable groups. This raises the question of autonomy, and to what degree can we truly be autonomous in the face of inequitable public policy? It is seemingly contradictory to expect communities to function autonomously and within the parameters of the law when the sociopolitical environment has been shown to disadvantage vulnerable sectors of those communities. While these are complex issues of social justice, of which driver licensing is one component, the present results support previous research that has identified inequity inherent within the licensing and justice system that is barrier to licence participation for vulnerable populations including but not limited to Aboriginal people (Cullen, Clapham, Byrne, et al., 2016; Cullen, Clapham, Hunter, et al., 2016; Elliot and Shananhan Research, 2008; Helps et al., 2008; Naylor, 2010; NSW Auditor General, 2013). Taken together this means that participation in licensing is not equitable and the impacts of reduced participation are having devastating consequences for individuals, families and communities but also far reaching consequences across the health, human service and justice systems. 
This study has several strengths and limitations. While this study sought to obtain a rich understanding of the impact licence participation, it focuses on Aboriginal communities in NSW and thereby does not explore generalisability to other cultural groups or populations (e.g. other Australian states). A limitation of the current study was the small sample of informants from government agencies, however the stories shared by these participants were detailed and gave a rich understanding of the socio-political context. The present results could be extended to include additional key policy makers to further explore the policy implications of licence participation across sectors. A final limitation of the present study is that it does not explore the impact of alternative transport options including ride sharing, which may be a viable form of transport and warrants further exploration within Aboriginal community contexts. Similarly, there is scope for future research to explore whether access to healthcare could be addressed by increased investment in mobile healthcare solutions, which could potentially reduce the reliance on private transport. Nevertheless, the current results indicate that reduced licence participation is impacting individuals, families and communities with an immense cost to multiple levels of the social ecology. Accordingly, policy should be directed at providing equitable participation in licensing to improve participation and alleviate burden. Licence participation cannot be relegated to simply a 'Transport' problem; given the multi-faceted nature of this issue, a collaborative intersectoral policy approach is recommended to achieve change. Future research in other Australian jurisdictions and other diverse contexts (e.g. remote communities) is advised to explore the benefits of licence participation at all levels of the social ecology in these contexts. Finally, future research incorporating an economic analysis of the health, justice and social inclusion costs of reduced licence participation in Aboriginal communities may provide policy makers with impetus to target change at improving access to licensing. 


\section{CONCLUSION}

There is growing recognition of the need for a strengths-based approach to Aboriginal health and well-being that incorporates intersectoral collaborative change to addressing underlying inequity. While previous research has revealed the barriers to licence participation, the present study explores the impacts of licence participation to individuals, families, communities and the socio-political environment. This has reinforced the importance of driver licensing to accessing services, employment and educational opportunities, which are known determinants of social inclusion, health and well-being. The present results extend previous research by demonstrating the impact of licence participation on cultural identity and community well-being. Further, reduced licence participation interacts with persistent inequity in the licensing and justice system and impacts on the capacity of individuals, families and communities to function autonomously within the parameters of the law. Addressing this complex issue of social justice is a prime example of the need for an intersectoral approach that targets change at the Health, Human Service and Justice systems.

Acknowledgements: The authors acknowledge the immense contribution of Rebekah Treacy, Jake Byrne, Rosemarie McBride, Alex Niki, Jennifer Rumbel, John Clarke, Louis Stanton, John Pocius, the Driving Change Youth Workers, Steering Committee, Investigative Committee and the Driving Change communities. 
TABLES

449 Table 1 Description of participant characteristics $(\mathrm{N}=38)$

\begin{tabular}{lr}
\hline Characteristic & $\mathrm{N}(\%)$ \\
\hline Gender (Female) & $27(71)$ \\
Identifies as Aboriginal and/or Torres Strait Islander & $31(82)$ \\
Urban & $9(24)$ \\
Licensed & $17(45)$ \\
\hline Government agency & $5(13)$ \\
Community member & $21(55)$ \\
Service delivery & $12(32)$ \\
\hline In-depth interview & $17(45)$ \\
Discussion group & $21(55)$ \\
\hline
\end{tabular}


Table 2 Impact of licence participation at all levels of the social ecology

\begin{tabular}{|l|l|l|}
\hline $\begin{array}{l}\text { Benefits of licence } \\
\text { participation }\end{array}$ & $\begin{array}{l}\text { Direct impact to individuals, families and } \\
\text { communities }\end{array}$ & $\begin{array}{l}\text { Departments and } \\
\text { Agencies }^{\mathrm{A}} \text { impacted }\end{array}$ \\
\hline $\begin{array}{l}\text { Increase access to } \\
\text { essential services e.g. } \\
\text { food, health }\end{array}$ & $\begin{array}{l}\text { Reduce the burden of chronic disease, } \\
\text { reduce reliance on community transport } \\
\text { particularly in areas with limited or no } \\
\text { public transport options }\end{array}$ & $\begin{array}{l}\text { Health, Human } \\
\text { Services, Transport }\end{array}$ \\
\hline $\begin{array}{l}\text { Increase access to } \\
\text { education }\end{array}$ & $\begin{array}{l}\text { Improve literacy, numeracy, employment } \\
\text { skills. Associated with improved } \\
\text { outcomes for health, employment and } \\
\text { reduced participation in crime }\end{array}$ & $\begin{array}{l}\text { Education, Human } \\
\text { Services, Justice }\end{array}$ \\
\hline Improve employability & $\begin{array}{l}\text { Health and financial benefits associated } \\
\text { with employment and reduced } \\
\text { participation in crime }\end{array}$ & $\begin{array}{l}\text { Human Services } \\
\text { Justice }\end{array}$ \\
\hline Improve social inclusion & $\begin{array}{l}\text { Improve wellbeing and opportunities to } \\
\text { participate in sporting, social and cultural } \\
\text { events with associated health benefits and } \\
\text { reduced participation in crime }\end{array}$ & $\begin{array}{l}\text { Health, Human } \\
\text { Services, Justice }\end{array}$ \\
\hline $\begin{array}{l}\text { Reduce unauthorised } \\
\text { driving offences and } \\
\text { secondary offending }\end{array}$ & $\begin{array}{l}\text { Reduce fines, sanctions, incarceration } \\
\text { rates and contact with the justice system }\end{array}$ & Justice ${ }^{\mathrm{C}}$, Transport \\
\hline $\begin{array}{l}\text { Reduce transport-related } \\
\text { morbidity and mortality }\end{array}$ & $\begin{array}{l}\text { Reduce burden of injury and premature } \\
\text { death, reduce contact with the justice } \\
\text { system }\end{array}$ & $\begin{array}{l}\text { Health, Transport, } \\
\text { Human Services, } \\
\text { Justice }\end{array}$ \\
\hline
\end{tabular}

${ }^{\mathrm{A}}$ Government (federal, state, local) departments and private agencies

$453 \quad{ }^{B}$ Including private job service providers

$454{ }^{c}$ Including Attorney-General's Department, corrective services, Police, State-debt Recovery

455 Office 
456 Figure 1 Benefits of licensing-related mobility

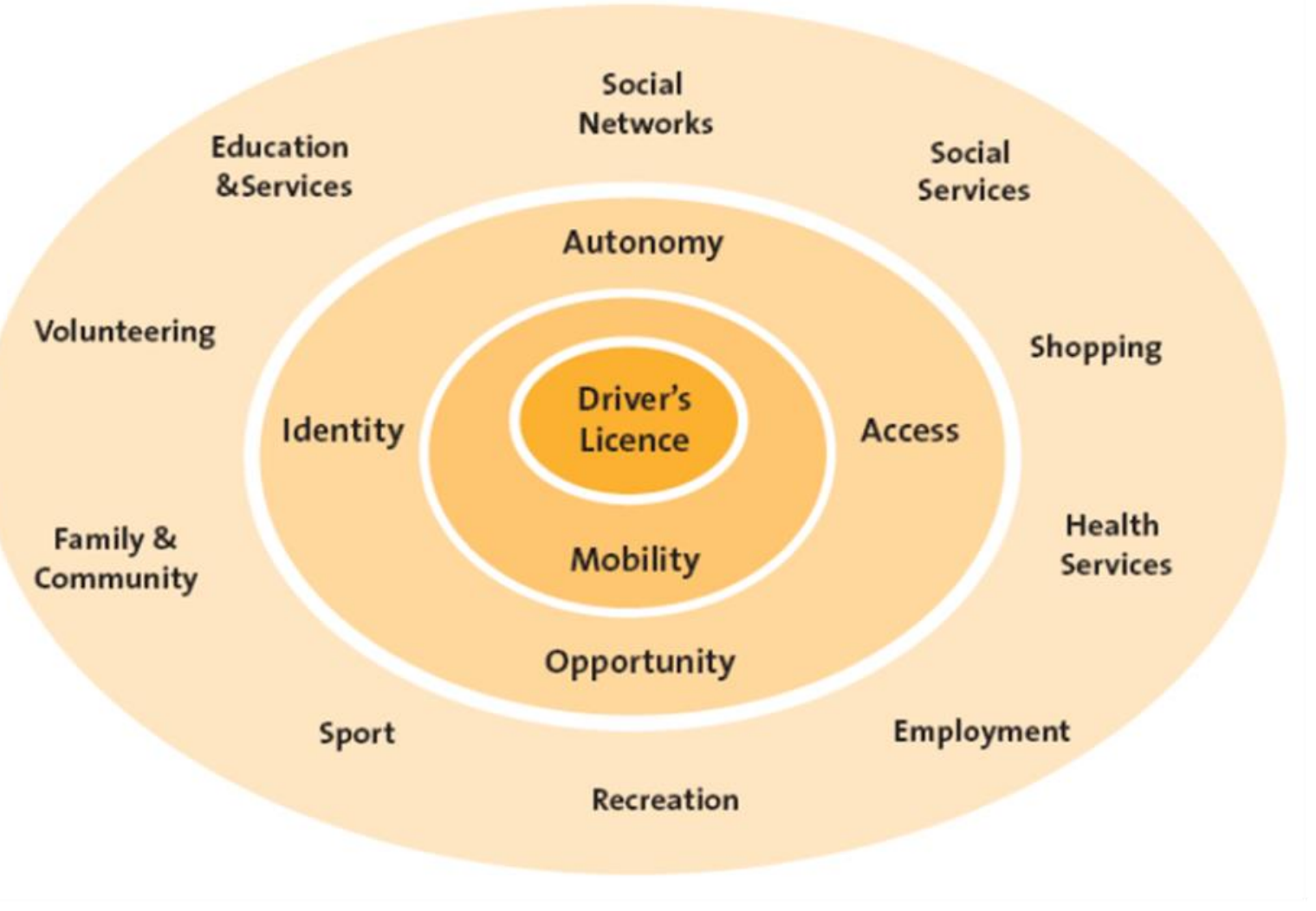

457

458 Source Kickbusch (2008, p. 51) 


\section{REFERENCES}

Anthony, T., \& Blagg, H. (2012). Addressing the "crime problem" of the Northern Territory Intervention: Alternate paths to regulating minor driving offences in remote Indigenous communities. (CRG 38/09-10). Criminology Research Advisory Council.

Australian Bureau of Statistics. (2010). 4704.0 - The Health and Welfare of Australia's Aboriginal and Torres Strait Islander Peoples, Oct 2010 Canberra: Retrieved from http://www.abs.gov.au/AUSSTATS/abs@.nsf/lookup/4704.0Main+Features10ct+2010.

Australian Bureau of Statistics. (2011). Methods of travel to work in 2011 (employed persons aged 15 years and over). Retrieved from http://www.abs.gov.au/websitedbs/censushome.nsf/home/mediafactsheets2nd/\$̧file/Topic \%20-\%20Method\%20of\%20Travel\%20to\%20Work.pdf.

Australian Bureau of Statistics. (2015a). Greater Taree Regional Profile. Retrieved from http://stat.abs.gov.au/itt/r.jsp?RegionSummary\&region=13380\&dataset=ABS REGIONAL L GA\&geoconcept=REGION\&datasetASGS=ABS REGIONAL ASGS\&datasetLGA=ABS REGIONA L LGA\&regionLGA=REGION\& regionASGS=REGION website: $\underline{w w w . a b s . g o v . a u}$

Australian Bureau of Statistics. (2015b). Wagga Regional Profile. Retrieved from http://stat.abs.gov.au/itt/r.jsp?RegionSummary\&region=17750\&dataset=ABS REGIONAL L GA\&geoconcept=REGION\&datasetASGS=ABS REGIONAL ASGS\&datasetLGA=ABS REGIONA L LGA\&regionLGA=REGION\& regionASGS=REGION website: www.abs.gov.au

Australian Institute of Health and Welfare. (2014). Aboriginal and Torres Strait Islander Health Performance Framework 2014 report: detailed analyses. Retrieved from http://www.aihw.gov.au/WorkArea/DownloadAsset.aspx?id=60129554004.

Australian Institute of Health and Welfare. (2015). The health and welfare of Australia's Aboriginal and Torres Strait Islander peoples 2015. (Cat. no. IHW 147.). Canberra: AlHW.

Baum, F., Lawless, A., Delany, T., MacDougall, C., Williams, C., Broderick, D., . . Popay, J. (2013). Evaluation of Health in All Policies: challenges, concepts, theory and application. Finland: Helsinki.

Cullen, P., Chevalier, A., Hunter, K., Gadsden, T., \& Ivers, R. (2017). 'The program was the solution to the problem': Process evaluation of a multi-site driver licensing program in remote communities. Journal of Transport and Health, 4, 81-89. doi: 10.1016/j.jth.2016.07.004

Cullen, P., Clapham, K., Byrne, J., Hunter, K., Senserrick, T., Keay, L., \& Ivers, R. (2016). The importance of context in logic model construction for a multi-site community-based Aboriginal driver licensing program. Evaluation and Program Planning, 57, 8-15. doi: http://dx.doi.org/10.1016/i.evalprogplan.2016.03.011

Cullen, P., Clapham, K., Hunter, K., Treacy, R., \& Ivers, R. (2016). Challenges to driver licensing participation for Aboriginal people in Australia: A systematic review of the literature. Int J Equity Health, 15(134). doi: 10.1186/s12939-016-0422-9

Currie, G., \& Senbergs, Z. (2007). Indigenous communities: Transport disadvantage and Aboriginal communities. In G. Currie, J. Stanley, \& J. Stanely (Eds.), No Way To Go: Transport and Social Disadvantage in Australian Communities. Clayton, Victoria: Monash University ePress.

Delbosc, A., \& Currie, G. (2011). Exploring the relative influences of transport disadvantage and social exclusion on well-being. Transport Policy, 18(4), 555-562. doi: http://dx.doi.org/10.1016/i.tranpol.2011.01.011

Edmonston, C. J., Rumble, N., Powell, J., Butler, S., Nona, H., Watson, B. C., \& Schonfeld, C. C. (2003). Working with Indigenous communities to improve driver licensing protocols and offender management. Paper presented at the 2003 Road Safety Research: Policing and Education Conference, Sydney, NSW.

Elliot and Shananhan Research. (2008). An investigation of Aboriginal driver licensing issues Aboriginal Licensing Final Report Sydney: NSW Roads and Traffic Authority. 
Golledge, E. (2006). Not such a fine thing! The impact of fines and the regulation of public space. Parity, 19(1), 58-59.

Helps, Y. L. M., Moller, J., Kowanko, I., Harrison, J. E., O’Donnell, K., \& de Crespigny, C. (2008). Aboriginal people travelling well: Issues of safety, transport and health. Canberra, ACT: Department of Infrastructure, Transport, Regional Development and Local Government.

Henley, G., \& Harrison, J. E. (2013). Injury of Aboriginal and Torres Strait Islander people due to transport: 2005-06 to 2009-10 Injury research and statistics series 85. Cat. no. INJCAT 161. Canberra: AlHW.

Ivers, R., Clapham, K., Senserrick, T., Lyford, M., \& Stevenson, M. (2008). Injury prevention in Australian Indigenous communities. Injury, 39, Supplement 5(0), S61-S67. doi: http://dx.doi.org/10.1016/S0020-1383(08)70030-5

Ivers, R., Hunter, K., Clapham, K., Helps, Y., Senserrick, T., Byrne, J., ... Harrison, J. E. (2016). Driver licensing: descriptive epidemiology of a social determinant of Aboriginal and Torres Strait Islander health. Australian and New Zealand Journal of Public Health, 40(4), 377-382. doi: 10.1111/1753-6405.12535

Ivers, R., Lyford, M., Johnson, J., Boufous, S., Senserrick, T., \& Clapham, K. (2011). Road safety and driver licensing in Aboriginal people in remote NSW. Paper presented at the Coalition for Research to Improve Aboriginal Health, Sydney, NSW.

Kickbusch, I. (2008). Healthy Societies: Addressing 21st century health challenges. Adelaide: Department of the Premier and Cabinet.

Kickbusch, I., \& Buckett, K. (2010). Health in All Policies: the evolution Implementing Health in All Policies: Adelaide 2010. Adelaide: Department of Health, Government of South Australia.

Kickbusch, I., McCann, W., \& Sherbon, T. (2008). Adelaide revisited: from healthy public policy to Health in All Policies. Health Promotion International, 23(1), 1-4. doi: 10.1093/heapro/dan006

Kok, G., Gottlieb, N. H., Commers, M., \& Smerecnik, C. (2008). The Ecological Approach in Health Promotion Programs: A Decade Later. American Journal of Health Promotion, 22(6), 437-442.

Lawless, A., Williams, C., Hurley, C., Wildgoose, D., Sawford, A., \& Kickbusch, I. (2012). Health in all polices: evaluating the South Australian approach to Intersectoral action for Health. Canadian Journal of Public Health, 103(Suppl. 1), S15-S19.

Naylor, B. (2010). L-plates, logbooks and losing-out: Regulating for safety - or creating new criminals? Alternative Law Journal, 35(2), 94-98.

NSW Auditor General. (2013). New South Wales Auditor-General's Report to Parliament: Improving Legal and Safe Driving Among Aboriginal People. Sydney, NSW: Audit Office of New South Wales.

Pollack, K. M., Frattaroli, S., Young, J. L., Dana-Sacco, G., \& Gielen, A. C. (2012). Motor Vehicle Deaths Among American Indian and Alaska Native Populations. Epidemiologic Reviews, 34(1), 73-88. doi: 10.1093/epirev/mxr019

QSR International Pty Ltd. (2012). NVivo qualitative data analysis software (Version 10).

Raerino, K., Macmillan, A. K., \& Jones, R. G. (2013). Indigenous Māori perspectives on urban transport patterns linked to health and wellbeing. Health \& Place, 23, 54-62. doi: http://dx.doi.org/10.1016/i.healthplace.2013.04.007

Richard, L., Potvin, L., Kishchuk, N., Prlic, H., \& Green, L. W. (1996). Assessment of the Integration of the Ecological Approach in Health Promotion Programs. American Journal of Health Promotion, 10(4), 318-328.

Rosier, K., \& McDonald, M. (2011). The relationship between transport and disadvantage in Australia. Melbourne: Australian Institute of Family Studies.

Scrimgeour, M., \& Scrimgeour, D. (2008). Health care access for Aboriginal and Torres Strait Islander people living in urban areas, and related research issues: a review of the literature. Darwin, Cooperative Research Centre for Aboriginal Health. 
100

101

102

103

104

105

106
Somssich, E. (2009). Driver training and licensing issues for indigenous people. Journal of the Australasian College of Road Safety, 20(1), 31-36.

United Nations. (2008). United Nations Declaration on the Rights of Indigenous Peoples. Retrieved from http://www.un.org/esa/socdev/unpfii/documents/DRIPS en.pdf website: www.un.org

Ware, V. (2013). Improving the accessibility of health services in urban and regional settings for Indigenous people. Closing the Gap Clearinghouse. Resource sheet no. 27. 